\title{
Heminthiasis in a Wild Rats (Rattus sp.) in Surabaya
}

\section{Helminthiasis pada Tikus Liar (Rattus sp.) di Surabaya}

\author{
${ }^{1)}$ Hemasayu Nirmala Putri, ${ }^{2)}$ Budiarto, ${ }^{3)}$ Arimbi, 4) Lucia Tri Suwanti, ${ }^{4)}$ Kusnoto, 5) Soeharsono \\ ${ }^{1)}$ Student, Faculty of Veterinary Medicine, Unviersitas Airlangga \\ ${ }^{2)}$ Department of Veterinary Public Health, Faculty of Veterinary Medicine, Unviersitas Airlangga \\ 3)Department of Veterinary Pathology, Faculty of Veterinary Medicine, Unviersitas Airlangga \\ 4)Department of Veterinary Parasitology, Faculty of Veterinary Medicine, Unviersitas Airlangga \\ 5)Department of Veterinary Anatomy, Faculty of Veterinary Medicine, Unviersitas Airlangga
}

Received: 06-08-2019, Accepted: 13-08-2019, Published Online: 16-08-2019

\begin{abstract}
The research was done to investigated and find out whether in the rat's (Rattus sp.) body in Surabaya contained zoonotic helminth.This research used 31 rats taken from North Surabaya, South Surabaya, East Surabaya, West Surabaya and Central Surabaya, regardless of gender and age. 1 sample from Mulyosari, 3 samples from Bratang, 7 samples from Pegirian, and 20 samples came from Keputran. The result of 31 samples of rat's digestive organs examine using a surgical method showed positive resulth of the presence of Hymenolepis diminutain the intestine and 5 positive samples were Capillaria hepatica, and then 25 positive samples were Taenia taeniaformis obtained from rat liver organs. From exploration using a microscope, 27 samples showed positive result in the presence of Capillaria hepatica's eggs. Helminth found in this research are Hymenolepis diminuta, Taenia taeniaformis. and Capillaria hepatica which are zoonotic.
\end{abstract}

Key words: Rattus sp., Hymenolepis diminuta, Taenia taeniaformis, Capillaria hepatica

\section{Pendahuluan}

Surabaya, merupakan ibukota provinsi Jawa Timur terkenal sebagai kota pelabuhan yang secara tidak langsung mengantarkan Surabaya sebagai kota perdagangan dan jasa sehingga dikenal sebagai kota yang strategis. Sebagai kota yang strategis, tentu tidak mengherankan apabila Surabaya digolongkan sebagai kota yang padat penduduk. Karena termasuk kota yang padat penduduk, tak dapat dipungkiri bahwa di Surabaya masih terdapat daerah daerah yang kurang terjaga kebersihannya seperti perkampungan padat penduduk dan pasar. Kurangnya kebersihan pada daerah tersebut menyebabkan banyak terdapat hewan hewan yang kemungkinan dapat menyebarkan penyakit, baik itu penyakit yang bersifat zoonosis maupun tidak seperti tikus.

Tikus atau Rattus sp. merupakan hewan yang sangat dikenal manusia karena beberapa jenis tikus tersebut hidup dalam lingkungan bersama dengan manusia. Hewan ini masuk dalam suku Muridae dan mempunyai kemampuan beradaptasi yang besar pada lingkungannya sehingga mempunyai penyebaran yang luas di dunia (Pisanu dkk., 2013).
Selain menimbulkan berbagai kerusakan dan gangguan kenyamanan, tikus juga memiliki peran yang penting dalam penyebaran penyakit menular pada manusia. Beberapa penyakit yang telah diketahui dapat ditularkan oleh tikus diantaranya, leptospirosis, rat-bite fever, Q-fever dan haemorrhagic fever (Coomansingh dkk., 2009). Selain diketahui dapat menularkan penyakit tersebut, di dalam tikus juga terdapat parasit baik itu enktoparasit maupun endoparasit. Ektoparasit yang dapat ditemui pada tikus yaitu Xenopsylla cheopsis, Stivalus cognatus, Polyplax spinulosa, Hoplopleura pasifica, larva tungau, tungau dan caplak (Ristiyanto, 2007). Sedangkan untuk infeksi endoparasit yang bersifat zoonosis yaitu Capillaria hepatica, Hymenolepis nana, $H$. diminuta and Trichinella spiralis (Stojcevic dkk., 2004). Endoparasit tersebut dapat ditularkan ke manusia melalui gigitan ektoparasit maupun penularan langsung melalui kontak dengan liur, feses, dan urin tikus yang telah terinfeksi (Ristiyanto, 2004).

Seorang anak laki - laki berusia empat tahun di Iran juga dilaporkan terinfeksi oleh cacing Capillaria hepatica setelah menderita demam intermiten selama dua bulan dan 
kehilangan berat badan sebanyak 1,5 kg. Anak tersebut di diagnosa terinfeksi cacing Capillaria hepatica setelah dilakukan pemeriksaan darah lengkap dan dilakukan biopsi pada hepar (Aghdam dkk., 2015).

Zoonosis merupakan penyakit dan infeksi yang secara alami dapat ditularkan dari hewanhewan vertebrata ke manusia dan atau sebaliknya. Pengertian tersebut juga mencakup keadaan dimana suatu makhluk hidup baik di dalam tubuh manusia maupun hewan. Zoonosis juga dapat berlaku bagi suatu organisme penyebab penyakit yang hidup pada suatu lingkungan seperti tanah, dan baik manusia maupun hewan dapat mengalami infeksi akibat adanya kontak langsung dengan tanah yang menjadi sumber infeksi tersebut. (Tri Wijayanti, 2010).

Selain kontak langsung dengan lingkungan, penyakit zoonosis juga dapat ditularkan melalui hewan. Sehingga penyakit zoonosis tersebut dapat dibedakan menjadi zoonosis yang berasal dari hewan liar, dari hewan yang dipelihara, dan zoonosis dari hewan yang tidak dipelihara tetapi tidak dipelihara seperti tikus. (Khairiyah, 2011).

Hingga saat ini, helminthiasis pada manusia di Surabaya belum pernah dilaporkan. Akan tetapi, pengamatan mengenai potensi risiko helminthiasis pada manusia tetap penting untuk dilakukan dikarenakan habitat tikus yang bersinggungan langsung dengan manusia dan kemungkinan besar dapat mengkontaminasi makanan dan minuman yang dikonsumsi melalui droplet yang dikeluarkan oleh tikus (Battersby dkk., 2002). Oleh karena itu penelitian ini dilakukan untuk mengetahui ada atau tidaknya infeksi cacing yang bersifat zoonosis pada daerah tersebut.

\section{Metode Penelitian}

\section{Tempat dan Waktu Penelitian}

Penelitian ini akan dilaksanakan pada bulan Mei hingga Juli 2018. Proses penelitian menggunakan metode dilaksanakan di Laboatorium Parasitologi Fakultas Kedokteran Hewan Universitas Airlangga.

\section{Alat dan Bahan Penelitian}

Alat yang digunakan adalah, kapas, scalpel, glove, pot salep, object glass, cover glass, mikroskop. Bahan yang digunakan dalam penelitian ini antara lain : organ pencernaan tikus (Rattus sp.), akuades, formalin, dietil eter.

\section{Metode Penelitian}

Penelitian ini merupakan penelitian observasi. Desain penelitian ini dipilih karena tidak dilakukan pretes terhadap sampel sebelum perlakuan karena telah dilakukan randomisasi baik pada kelompok eksperimen dan kelompok kontrol; kelompok-kelompok tersebut dianggap sama sebelum dilakukan perlakuan.

Tikus dikoleksi dari pasar di berbagai daerah di Surabaya menggunakan jebakan tikus. Setelah tikus dikoleksi, kemudian dibawa menuju Fakultas Kedokteran Hewan Universitas Airlangga untuk dilaksanakan penelitian. Sebelum dilaksanakan pembedahan untuk melangsungkan penelitian, tikus di euthanasia terlebih dahulu menggunakan dietil ether. Setelah tikus tidak sadarkan diri, kemudian dilakukan pembedahan dimulai dari abdomen yang kemudian diteruskan menuju thorax. Kemudian seluruh saluran pencernaan diambil dan dibedah menggunakan gunting tajam tumpul serta diamati dengan seksama apabila terdapat cacing. Cacing yang diperoleh dari membedah saluran pencernaan tikus tersebut kemudian dimasukkan ke dalam larutan $\mathrm{NaCl}$ fisiologis yang kemudian dipersiapkan untuk pembuatan preparat cacing permanen.

\section{Analisis Data}

Data yang sudah ada kemudian dianalisis menggunakan metode deskriptif.

\section{Hasil dan Pembahasan}

Terdapat 31 sampel tikus, satu sampel berasal dari Mulyosari, tiga sampel berasal dari Bratang, tujuh sampel berasal dari Pegirian, dan 20 sampel berasal dari Keputran. Berikut ini adalah tabel hasil perolehan cacing pada tikus yang telah diteliti.

Tabel 1. Hasil Identifikasi Cacing Pada Tikus

\begin{tabular}{|c|c|c|c|c|c|}
\hline \multirow{3}{*}{ Tempat } & \multirow{3}{*}{ Jumlah Tikus } & \multicolumn{4}{|c|}{ Jenis Cacing } \\
\hline & & \multirow{2}{*}{ H. diminuta } & \multirow{2}{*}{ T. taeniaformis } & \multicolumn{2}{|c|}{ C. Hepatica } \\
\hline & & & & Cacing & Telur \\
\hline Mulyosari & 1 & $1(100 \%)$ & $(0 \%)$ & $(0 \%)$ & $1(100 \%)$ \\
\hline Bratang & 3 & $2(66,6 \%)$ & $1(33,3 \%)$ & $(0 \%)$ & $2(66,6 \%)$ \\
\hline Pegirian & 7 & $4(57,1 \%)$ & $4(57,1 \%)$ & $2(28,5 \%)$ & $4(57,1 \%)$ \\
\hline Keputran & 20 & $20(100 \%)$ & $20(100 \%)$ & $2(10 \%)$ & $20(100 \%)$ \\
\hline Total & 31 & $27(87,09 \%)$ & $25(80,6 \%)$ & $4(12,9 \%)$ & $27(87,09 \%)$ \\
\hline
\end{tabular}


Berdasarkan Tabel 1, prevalensi cacing Hymenolepis diminuta adalah $87,09 \%$, Taenia taeniaformis 80, 6\%, dan untuk Capillaria hepatica 87,09. Hal ini membukti kan bahwa dalam saluran pencernaan tikus yang berada di Surabaya dapat terinfeksi oleh cacing yang bersifat zoonosis, serta dapat terinfeksi lebih dari satu cacing.
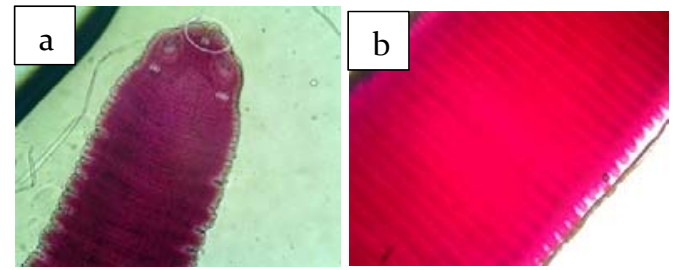

Gambar 1. Cacing Hymenolepis diminuta dewasa. a. Anterior $H$. diminuta dengan perbesaran 100 kali dengan pewarnaan karmin. (i) Scolex (ii) \& (iii) Sucker. b. H. diminuta dengan perbesaran 100 kali dengan pewarnaan karmin.

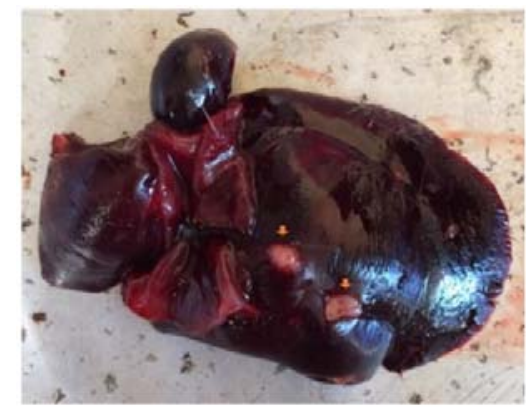

Gambar 2. Hepar tikus. Makrokopis hepar tikus yang terinfeksi oleh cacing T. taeniaformis, tanda panah merupakan kista berwarna putih yang apabila disayat menggunakan scalpel akan mengeluarkan cacing T. taeniaformis.

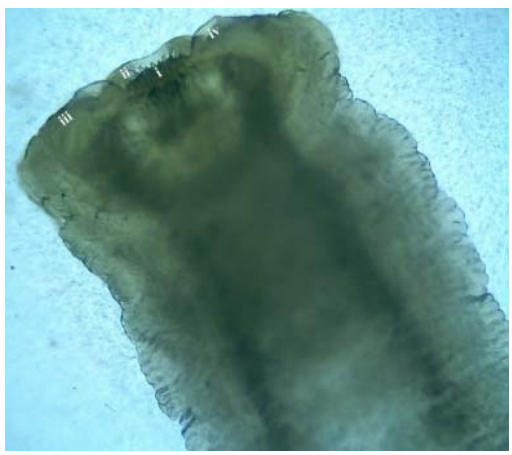

Gambar 3. Anterior Cacing Taenia taeniaformis. Anterior T. taeniaformis dengan perbesaran 40 kali, tanpa menggunakan pewarnaan (i) merupakan scolex, (ii) (iii) \& (iv) merupakan sucker.

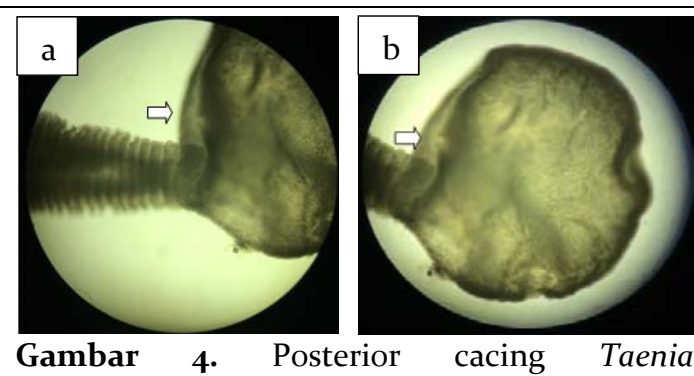
taeniaformis. a dan b merupakan bagian posterior dari cacing T. taeniaformis perbesaran 4o kali tanpa dilakukan pewarnaan. Bagian yang ditunjuk dengan tanda panah merupakan bentuk bel yang merupakan bentukan khas dari cacing T. taeniaformis.
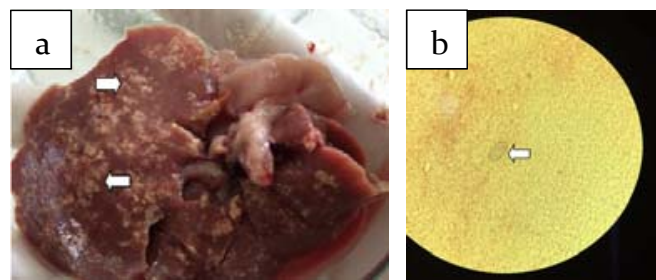

Gambar 5. Hepar tikus. a. Makroskopis hepar tikus yang terinfeksi cacing $C$. hepatica, tanda panah menunjukkan bentukan nekrosis multifokal berwarna kuning pucat yaitu salah satu ciri - ciri dari hepar yang telah terinfeksi oleh cacing $C$. hepatica. b. Telur $C$. hepatica yang ditemukan pada hepar tikus, menggunakan perbesaran 100 kali.
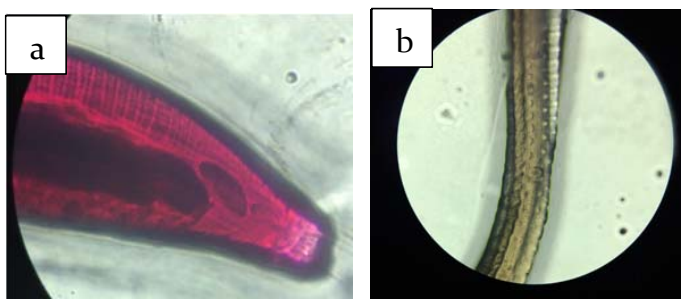

Gambar 6. Cacing Capillaria hepatica dewasa. a. Anterior cacing Capillaria hepatia perbesaran 100 kali dengan pewarnaan karmin b. Posterior cacing Capillaria hepatica perbesaran 100 kali dengan pewarnaan karmin.

Hasil penelitian dari 31 sampel organ pencernaan tikus yang diperiksa menggunakan metode pembedahan menunjukkan hasil positif adanya cacing Hymenolepis diminuta pada usus dan lima sampel positif terdapat cacing Capillaria hepatia. Kemudian sebanyak 25 sampel positif terdapat cacing Taenia taeniaformis yang didapatkan pada organ hepar tikus. Selain dilakukan pemeriksaan menggunakan metode pembedahan, proses pemeriksaan 
juga dilakukan dengan cara eksplorasi menggunakan mikroskop. Dari eksplorasi menggunakan mikroskop tersebut didapatkan 27 sampel menunjukkan hasil positif adanya telur cacing Capillaria hepatica.

Cacing yang ditemukan pada usus tikus tersebut diidentifikasi sebagai cacing $H$. diminuta karena ukuran panjang antara $20-40$ $\mathrm{mm}$, pada bagian anterior menunjukkan adanya scolex dengan bentuk menyerupai gada dengan rostelum apical yang rudimenter, tidak memiliki kait dan dilengkapi dengan empat batil isap (Prasetyo, 2003).

Kemudian pada hepar tikus terdapat suatu bentukan bulat berwarna putih berukuran sekitar 5 - $10 \mathrm{~mm}$ yang apabila disayat menggunakan blade terdapat larva cacing yang diidentifikasi sebagai spesies T. taeniaformis. Cacing tersebut diidentifikasi sebagai cacing Taenia taeniaformis dikarenakan terdapat bentukan khas pada bagian posterior yang menyerupai bel. Scolex berukuran besar dengan double circlet dan mempunyai 30 - 40 kait. Mempunyai 4 sucker dan tidak memiliki leher (Al-Jashamy dkk., 2017).

Pada hepar tikus terdapat lesi multifokal berwarna kuning pucat. Lesi multifokal berwarna kuning pucat ini merupakan indikasi adanya infeksi oleh cacing Capillaria hepatica (Berentsen dkk., 2015). Setelah diperiksa menggunakan mikroskop, hasil positif ditemukan telur cacing Capillaria hepatica. Hal ini ditunjukkan dengan ciri - ciri telur berbentuk oval, berdinding ganda dengan outer striated wall, serta terdapat polar plugs pada kedua sisinya (Nabi dkk., 2007).

\section{Kesimpulan}

Terdapat cacing bersifat zoonosis yang ditemukan pada tikus di Surabaya. Terdapat tiga spesies cacing berbeda yang ditemukan pada saluran pencernaan tikus Surabaya yaitu Hymenolepis diminuta, Taenia taeniaformis, dan Capillaria hepatica.

\section{Daftar Pustaka}

Aghdam, M. K., A. Karimi, A. Amanati, J. Ghoroubi, M. Khoddami, B. S. Shamsian, A. Shamsizadeh, S. Z. Far. 2015. Capillaria hepatia, A Case Report and Review of the Literatures. Arch Pediatr Infect Dis : 3(2): e19398.

Al-Jashamy, K., M. N. Islam. 2007. Morphological Study Of Taenia taeniaformis Scolex Under Scanning Electron Microscopy Using Hexamethyldislazane. Annals Of Microscopy. Vol. 7.

Battersby, S. A., R. Parsons, J. P. Webster. 2002. Urban Rat Infestations and The Risk to Public Health. Journal of Environmental Health Research; 1: 4-12.

Coomansingh, C., R. D. Pinckney, M. I. Bhaiyat, A. Chikweto, S. Bitner, A. Baffa, R. Sharma. 2009. Prevalence of Endoparasites in Wild Rats in Grenada. West Indian Veterinary Journal; 9(1): 17-21.

Khairiyah. 2011. Zoonosis dan Upaya Pencegahannya (Kasus Sumatra Utara). Jurnal Litbang Pertanian, 30(3).

Nabi, F., H. K. Palaha., D. Sekhsaria., A. Chiatale. 2007. Capillaria hepatica Infestation. Indian Pediatrics. Vol. 44.

Ristiyanto, Damar T. B., Farida D. H., Soenarto N. 2004. Keanekaragaman Ektoparasit pada Tikus Rumah Rattus Tanezumi dan Tikus Polinesia Rattus Exulans di Daerah Enzootik Pes Lereng Gunung Merapi, Jawa Tengah. Jurnal Ekologi Kesehatan Volume 3 Nomor 2.

Ristiyanto. 2007. Modul 3 Pelatihan Rodensia.

Stojcevic, D, Mihaljevic, Z., Marinculic, A. 2004. Parasitological Survey of Rats in Rural Regions of Croatia. Vet. Med. - Czech; 3: 70-4. 